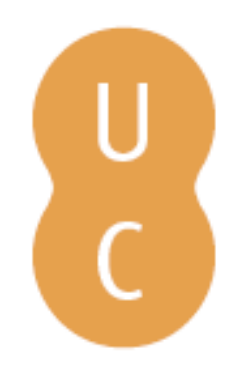

\title{
nombalina
}

\section{O trabalho de campo no ensino da Geologia: um estudo com alunos do $7^{\circ}$ ano de escolaridade}

\author{
Autor(es): $\quad$ Correia, Gina; Gomes, Celeste \\ Publicado por: Imprensa da Universidade de Coimbra; Laboratório de Radioactividade \\ URL \\ persistente: \\ Natural da Universidade de Coimbra \\ DOI: $\quad$ DOI:http://dx.doi.org/10.14195/978-989-26-1009-2_12 \\ Accessed : $\quad$ 26-Apr-2023 03:00:51
}

A navegação consulta e descarregamento dos títulos inseridos nas Bibliotecas Digitais UC Digitalis, UC Pombalina e UC Impactum, pressupõem a aceitação plena e sem reservas dos Termos e Condições de Uso destas Bibliotecas Digitais, disponíveis em https://digitalis.uc.pt/pt-pt/termos.

Conforme exposto nos referidos Termos e Condições de Uso, o descarregamento de títulos de acesso restrito requer uma licença válida de autorização devendo o utilizador aceder ao(s) documento(s) a partir de um endereço de IP da instituição detentora da supramencionada licença.

Ao utilizador é apenas permitido o descarregamento para uso pessoal, pelo que o emprego do(s) título(s) descarregado(s) para outro fim, designadamente comercial, carece de autorização do respetivo autor ou editor da obra.

Na medida em que todas as obras da UC Digitalis se encontram protegidas pelo Código do Direito de Autor e Direitos Conexos e demais legislação aplicável, toda a cópia, parcial ou total, deste documento, nos casos em que é legalmente admitida, deverá conter ou fazer-se acompanhar por este aviso.

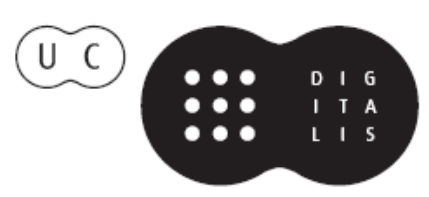




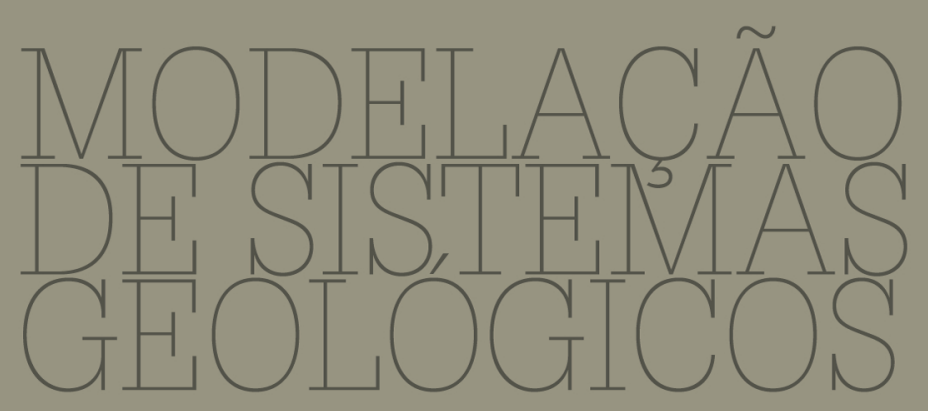

Homenagem ao Professor Doutor Manuel Maria Godinho

L.J.P.F. Neves, A.J.S.C. Pereira,

C.S.R. Gomes, L.C.G. Pereira,

A.O. TAVARES

IMPRENSA DA UNIVERSIDADE DE COIMBRA

CoImBra University Press 


\title{
MODELAÇÃO \\ DE SISTEMAS \\ GEOLÓGICOS
}

Homenagem ao Professor Manuel Maria Godinho

\section{O trabalho de campo no Ensino da Geologia. Um estudo com alunos do $7^{\circ}$ ano de escolaridade}

\author{
Gina Correia ${ }^{1}$; Celeste Gomes ${ }^{2}$ \\ ${ }^{1}$ Departamento de Ciências da Terra Universidade de Coimbra, Escola EB 2,3/S Dr. José Leite de \\ Vasconcelos, Tarouca, PORTUGAL, gina_maria@sapo.pt \\ ${ }^{2}$ Centro de Geofísica, Departamento de Ciências da Terra, Universidade de Coimbra, PORTUGAL, \\ romualdo@dct.uc.pt
}

Palavras-chave: Ensino da Geologia, Trabalho de campo, Modelo de Orion

\section{Resumo}

As orientações curriculares, bem como a necessidade de recorrer a estratégias motivadoras para o ensino de temas de Geologia, têm vindo a fomentar as actividades exteriores à sala de aula, no ensino básico e secundário. O diagnóstico relativamente a estas actividades foi efectuado e as vantagens foram superiores aos constrangimentos. Neste estudo apresenta-se uma aula de campo elaborada para alunos do $7 .^{\circ}$ ano de escolaridade, na disciplina de Ciências Naturais, realizada no final do ano lectivo 2009/2010, numa escola do Norte de Portugal. A organização do trabalho de campo seguiu as orientações do modelo de Orion e revelou-se uma estratégia motivadora para o desenvolvimento de competências.

Key-words: Geology Education, Fieldwork, Orion model

\begin{abstract}
:
Curriculum guidelines as well as the need for motivational strategies in teaching themes of Geology have led to the promotion/increase of activities outside the classroom, both in elementary as well as in secondary levels of education. The conclusions have been drawn and the benefits associated to these activities surpass any drawbacks. In this paper, we present a field class designed for $7^{\text {th }}$ year Science students, which was held at the end of the 2009/2010 school year, by a school in the north of Portugal. The organization of the field work followed the guidelines of the model of Orion and proved to be a motivational strategy for the development of competences.
\end{abstract}

\section{Introdução}

Para o ensino e a aprendizagem de temas de Geologia, os currículos apelam para a necessidade de complementar as actividades em contexto de sala de 
aula com o desenvolvimento de trabalho prático (TP). Este terá de ir além do trabalho laboratorial ou de outros trabalhos práticos desenvolvidos habitualmente em ambiente interior à Escola e sair para o exterior com as designadas aulas de campo.

A reorganização curricular, tanto do ensino básico como do secundário, tem destacado a relevância do trabalho de campo (TC) no ensino da Geologia, recorrendo a uma maior relação escola-meio envolvente. Del Cármen e Pedrinaci (1997) consideram que, no processo de ensino, se deverá explorar o meio que rodeia o aluno, permitindo-lhe que efectue as suas primeiras interpretações e que aprenda a apreciá-lo através da sua observação. Orion (2001) defende um processo de aprendizagem que deveria iniciar-se com uma fase de "construção de sentido", a ser conduzida, por exemplo, num ambiente de exterior.

Neste contexto, familiarizar o aluno com o espaço envolvente e, ao mesmo tempo, promover aprendizagens sobre a Geologia da região poderão constituir uma mais-valia e um incentivo para a compreensão de processos e objectos leccionados em contexto de sala de aula. A disciplina de Ciências Naturais para o $7 .^{\circ}$ ano de escolaridade inclui conteúdos que visam, maioritariamente, o ensino da Geologia. O objectivo principal deste trabalho é apresentar uma aula de campo planificada para alunos do $7^{\circ}$ ano de escolaridade, seguindo as orientações do modelo de Orion (1989), enquanto estratégia motivadora para o ensino da Geologia.

\section{O Trabalho de Campo e o Ensino e Aprendizagem em Geologia}

Os currículos das disciplinas de Geologia apontam a necessidade de desenvolver TP como complemento ao ensino mais teórico. O TP, segundo Hodson (1988), inclui o trabalho de laboratório (TL) e o TC, com componentes experimentais ou não, ou seja, incorpora todas as actividades nas quais os discentes envolvem simultaneamente o domínio psicomotor, cognitivo e afectivo. O mesmo autor define TL como aquele que se realiza num laboratório ou numa sala de aula normal, utilizando materiais de laboratório. $\mathrm{O}$ TC surge como o que envolve actividades exteriores à sala de aula (Orion, 2001), estando incluídas as aulas de campo, as visitas a museus, a jardins zoológicos e botânicos, etc. $\mathrm{Na}$ mesma linha de pensamento, Dourado (2001, p. 14) afirma que "o critério principal para assumir uma actividade como laboratorial ou de campo diz respeito ao local onde a mesma se desenvolve". Por último, o trabalho experimental (TE) pode decorrer em qualquer espaço físico, ou seja pode ser laboratorial ou de 
campo, desde que envolva o controlo e a manipulação de variáveis (Hodson, 1988).

Contudo, as práticas de ensino adoptadas durante grande parte do século XX não atribuíam ao TP a importância necessária para que fosse aplicado nas várias áreas curriculares e nos diferentes níveis de escolaridade. Também a formação inicial de professores não incentivava para a necessidade deste tipo de ensino e as condições físicas das escolas surgiam igualmente como barreira à sua realização. Se o trabalho de laboratório e/ou experimental faziam parte das práticas de alguns professores mais audaciosos, o mesmo não acontecia com o TC, sendo este o mais negligenciado. A título de exemplo, entre 1930 e 1980, foram descritos apenas 43 estudos empíricos envolvendo trabalho exterior à sala de aula, comparando, na sua maioria, "viagens de campo" com outros métodos de ensino (Mason, 1980). Ainda hoje, muitos docentes confundem as aulas de campo com as visitas de estudo comuns.

Com o desenvolvimento, em especial nas últimas décadas do Séc. XX, dos modelos de ensino ditos construtivistas, o TP ganhou novo alento. Em Portugal, surgiram, nos currículos do ensino secundário, as disciplinas de Técnicas Laboratoriais de Biologia e de Geologia que serviam de suporte às disciplinas teóricas. Contudo, nas disciplinas de Técnicas, o TC foi uma vez mais relegado para segundo plano, sendo as aulas fundamentalmente de carácter laboratorial e/ou experimental. No entanto, a vertente prática no ensino das ciências, nomeadamente da Geologia, não deve ser exclusivamente laboratorial. A complexidade dos processos geológicos, nos quais se destacam as escalas, de tempo e espaço, torna impossível, muitas vezes, a sua reprodução num laboratório. Assim, importa mostrar aos alunos a importância do TC, como complementar ao TL e à aprendizagem mais teórica, com o objectivo final de promover uma compreensão efectiva dos processos geológicos e dos seus resultados (Ruivo et al., 1995).

No mesmo sentido, mais recentemente, o programa de Biologia e Geologia, resultado da última reforma para o ensino secundário, refere, num apelo directo ao recurso ao TC como estratégia didáctica a privilegiar neste nível de ensino, que "no caso específico da Geologia um dos aspectos que, em termos metodológicos, mais importa destacar é o das designadas actividades de campo." (Silva et al., 2001 p. 12).

Porém, leccionar num ambiente exterior ao contexto da sala de aula requer uma preparação adequada, pois "the outdoors is a very complicated learning environment, since it includes a large number of stimuli, which can easily distract students from meaningful learning." (Orion, 2001 p. 270). Deste modo, todas as aulas de campo deverão ter uma preparação correcta e 
definição dos objectivos e competências a atingir pelos discentes, de forma a modificar a ideia de que uma aula de campo possa ser um simples passeio pelo campo.

\section{Trabalho de Campo como Estratégia Didáctica}

Embora o valor e as vantagens do TC para o ensino da Geologia tenham sido reconhecidas, esta valorização não se tem reflectido nas actividades escolares (Orion, 1993). Das vantagens apresentadas por diversos autores, Orion e Hofstein (1991) referem estudos nos quais, os alunos participantes em actividades de TC apresentam maiores capacidades de observação, memorização e de relembrar factos. Também Orion (1993) afirma que as experiências directas com os processos e objectos concretos ajudam à construção de conceitos, favorecendo também a sua memorização. Para Leite e Santos (2004 p. 1), "O trabalho de campo apela ao cruzamento das diferentes ciências para a compreensão da realidade, estimula a tomada de iniciativa e a tomada de decisão. Introduz rupturas no rame-rame organizativo das instituições educativas abrindo alternativas". Marques e Praia (2009) defendem que esta estratégia promove um envolvimento mais efectivo no processo de aprendizagem e no trabalho cooperativo entre alunos e melhora a relação destes com o professor.

O TC ocorre usualmente no final da leccionação de um determinado conteúdo, considerando-se uma recompensa para os alunos (Orion, 1989, 1993 e 2001). Outras vezes, ocorre unicamente como suporte do TL, sendo utilizado apenas para recolha de materiais para análise no laboratório (Dourado, 2001).

As razões apontadas, pelos professores, para a não realização de aulas de campo são diversas. Orion (2001) justifica a situação assegurando que existem conflitos de interesses entre as necessidades educativas e dificuldades administrativas ou pessoais. As dificuldades de ordem financeira, os condicionalismos legais, nomeadamente, a responsabilidade civil para com os alunos, ou a rigidez dos horários das escolas, apresentamse como obstáculos administrativos com que os docentes têm de lidar quando pretendem preparar e implementar uma aula de campo. O mesmo autor refere, como dificuldades pessoais, a falta de confiança que os professores têm em leccionar no espaço exterior à sala de aula, apreensão que se deve, por vezes, ao facto de nunca terem aprendido a ensinar em ambientes de exterior. 


\section{Organizar uma Aula de Campo}

As aulas de campo são uma das actividades mais complexas e dispendiosas do sistema de ensino. Por isso, torna-se importante obter bons resultados educacionais para justificar o investimento (Orion e Hofstein, 1994).

As actividades de TC deverão ser contextualizadas e integradas nos currículos. Este tipo de trabalho deverá ser introduzido cedo no processo de ensino e aprendizagem sem ser, no entanto, uma das primeiras actividades (Orion, 1989, 1993 e 2001). Seguindo esta linha de pensamento, este autor sugere um modelo prático de integração das actividades de aprendizagem em espaços de interior e de exterior, atribuindo ao professor a tarefa de fazer com que estas actividades se complementem. Assim, o TL ou outras actividades práticas que possam ocorrer na sala de aula poderão complementar as actividades de TC. No mesmo sentido, a preparação de uma "saída de campo" implica a planificação de actividades características do campo, no entanto, também deverão ser perspectivadas outras actividades que posteriormente poderão ser desenvolvidas no laboratório (Dourado, 2001).

O modelo proposto por Orion (1989) consiste numa representação em espiral de três fases/etapas devidamente identificadas: a fase de preparação; a aula de campo; e a fase de síntese. Cada uma destas decorre num momento concreto e em sequência para que a fase anterior funcione como uma ponte para a fase posterior, com o objectivo final de rentabilizar o mais possível a aula de campo. Neste modelo há uma progressão gradual do conhecimento, de um nível mais concreto para um mais abstracto.

A fase de preparação, cujo papel principal é orientar os alunos para a aula de campo, decorre no espaço da sala de aula ou de laboratório, onde são trabalhadas componentes correspondentes ao conhecimento concreto. Esta torna-se importante, na medida em que minimiza o efeito negativo do designado "novelty space" (espaço novidade), na construção de conhecimentos novos, facilitando uma aprendizagem significativa durante a actividade de exterior (Orion, 1989, 1993 e 2001). A capacidade de aprendizagem dos alunos no campo é influenciada, tanto pelos seus conhecimentos prévios, como pelas experiências anteriores (Orion et al., 1986). A estes, Orion e Hofstein (1994) adicionam aspectos como os contactos anteriores com a área de estudo e as atitudes face aos conteúdos a estudar durante a aula de campo e à aula propriamente dita. Estas características agrupam-se em três factores que definem o "espaço novidade" de uma aula de campo: os factores psicológicos; geográficos; e cognitivos (Orion, 1993) (Figura 1). 


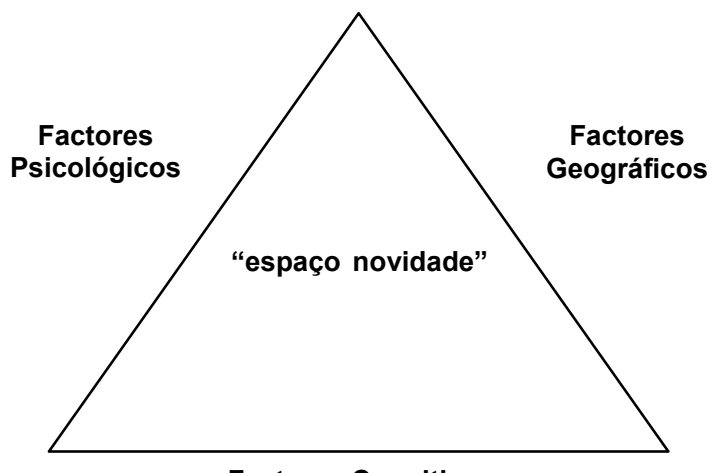

Factores Cognitivos

Figura 1. Representação esquemática dos factores que definem o "espaço novidade" (adaptado de Orion, 1993).

Segue-se a aula de campo, que constitui a fase mais importante deste modelo e que decorre num ambiente de exterior. Nesta fase, os alunos irão interagir directamente com os objectos e processos em estudo, avançando para um nível mais elevado de conhecimento Por último, surge a fase de síntese, na qual se trabalham os conceitos mais complexos relativos aos conhecimentos mais abstractos (Orion, 1993). Esta fase processa-se novamente no espaço de interior, corresponde a uma sinopse do trabalho realizado, podendo envolver o estudo de amostras e outros materiais obtidos na aula de campo, palestras, discussões e apresentação de diapositivos, entre outras actividades.

\section{Planificação de um Trabalho de Campo na Serra de Santa Helena - Tarouca}

$\mathrm{Na}$ planificação do trabalho de campo foram seguidas as indicações propostas nas orientações curriculares e no modelo de Orion. Os alunos, num total de 16 , pertenciam a uma turma do $7 .^{\circ}$ ano de escolaridade do ensino regular e as aulas decorreram no final do $3^{\circ}$ período, no âmbito da disciplina de Ciências Naturais, para sistematização de conceitos leccionados durante o ano lectivo. A avaliação da actividade foi efectuada com base no registo, em grelhas de observação de aula, e nas respostas dos alunos às questões apresentadas no guia de campo, para as diferentes paragens. 


\section{Desenvolvimento}

O modelo de desenvolvimento e implementação de aulas de campo assenta numa complementarização entre actividades de interior, laboratoriais, experimentais ou não, e actividades de exterior (Orion, 1993). Este modelo baseia-se em conclusões de estudos anteriores, bem como em critérios de natureza administrativa, docente, curricular e educacional.

Planificação

1. Organização hierárquica dos conceitos curriculares partindo, sempre que possível, do mais concreto para o mais abstracto.

Foram seleccionados os conteúdos e conceitos, definido o calendário em que estes deveriam ser estudados, durante o período de tempo em que decorreu a actividade, incluindo a preparação e a síntese, e os objectivos.

2. Selecção da área de estudo para a aula de campo.

Foi seleccionada a Serra de Santa Helena, no concelho de Tarouca, pelas potencialidades geológico-didácticas e pela proximidade geográfica da Escola.

3. Reconhecimento e definição do percurso (Figura 2).

Foi feito um reconhecimento in situ para definir o percurso, recorrendo à Carta Geológica de Lamego (14-A), à escala 1/50 000 (Teixeira et al., 1969) e ao mapa do site Google Earth.

4. Adequação dos conceitos curriculares às várias paragens.

Foram seleccionados, para cada paragem, os conceitos específicos e as questões a incluir no guia de campo do aluno.

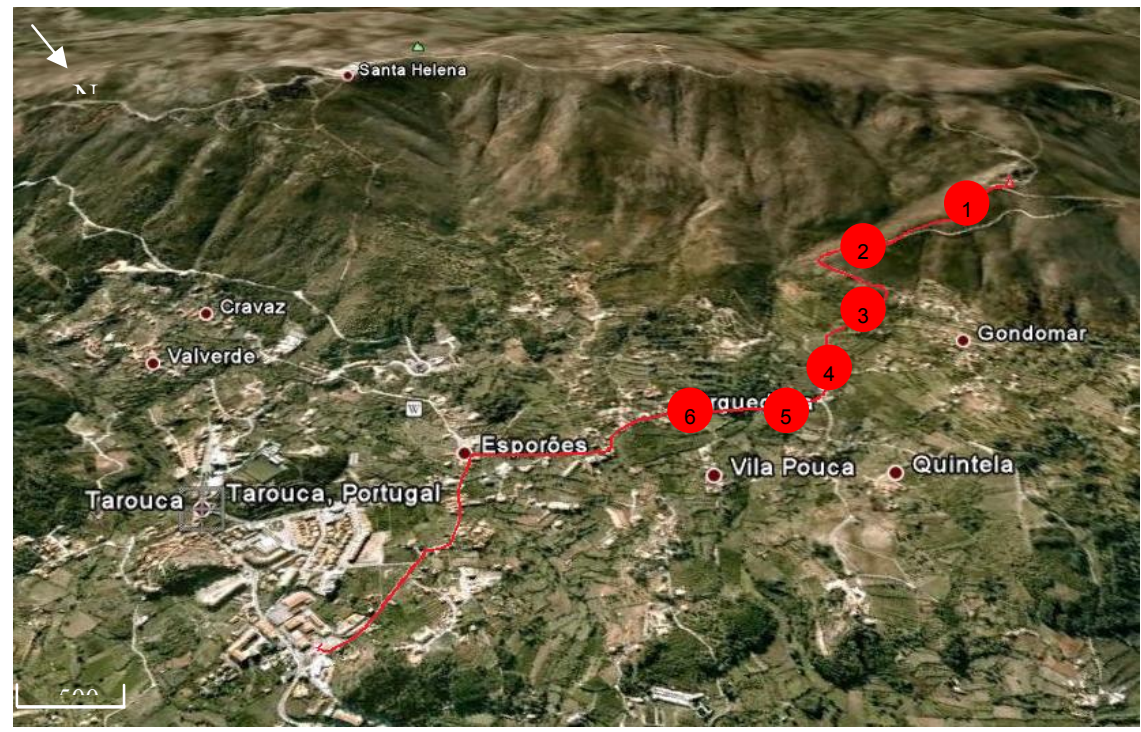

Figura 2. Itinerário seleccionado. 


\section{Organização do roteiro.}

Foi definido o percurso e seleccionados os seis locais de paragem intercalados por um período aproximado de 15 min entre eles. O itinerário foi integralmente definido em vias de acesso alcatroadas ou em terra batida, facilitando o acesso e minimizando os riscos de acidente. Esta opção foi viabilizada, pois cumpria os objectivos previamente definidos para a aula de campo e os aspectos geológicos eram de fácil observação. alunos.

6. Selecção e construção de materiais de apoio para o professor e

Foi construído um guia de campo do aluno, pela professora, que serviu de orientação e de suporte ao trabalho realizado na aula de campo.

\section{Fase de preparação}

Esta fase iniciou-se com a definição dos objectivos e a selecção criteriosa da área de estudo. O percurso foi definido com seis paragens de modo a incluir os conceitos curriculares a leccionar. Depois de planificado o roteiro e de uma primeira visita a todo o percurso foi construído o Guia de Campo com as tarefas a concretizar.

A seguir efectuou-se a análise prévia do percurso, com os discentes, acompanhada da iniciação à leitura e análise da Carta Geológica de Lamego (Teixeira et al., 1969), da identificação do percurso no site do Google Earth e da observação de fotografias, obtidas durante o trabalho de campo realizado previamente pela professora. Este conjunto de acções teve como objectivo familiarizar o aluno com o espaço da aula de campo e minimizar o "novelty space".

$\mathrm{Na}$ fase de preparação foram dadas indicações sobre: as regras a adoptar, os princípios éticos de actuação do geólogo no campo, as medidas de segurança, o vestuário a usar durante a aula de campo e os materiais necessários (máquina fotográfica, sacos de plástico, jornais velhos, etiquetas autocolantes e marcador para fazer fotos e amostrar as litologias observadas).

\section{Aula de campo}

Os objectivos definidos para a aula de campo foram os seguintes: 1) observar e interpretar a geomorfologia geral da Serra de Santa Helena; 2) identificar e interpretar estruturas tectónicas; 3) identificar diferentes tipos de rochas em afloramento; 4) recolher amostras de mão de rochas 
magmáticas e metamórficas; e 5) consolidar e aplicar aprendizagens realizadas ao longo do $7^{\circ}$ ano de escolaridade.

Em cada paragem, os alunos foram confrontados com exemplos leccionados anteriormente, em contexto de sala de aula, e tiveram de observar, interpretar e responder às questões colocadas no guia de campo (Figura 3). A classificação obtida nas respostas a este guia foi considerada na avaliação final da disciplina.

\section{LOCAL DE OBSERVAČ̃̃̃ 3: Zona de contacto entre quartzitos e granitos}

Conceitos importantes:

Diáclases - Fracturas, apenas com abertura, nas rochas.

Granito - Rocha magmática plutónica (intrusiva) formada a partir de solidificação do magma em profundidade. Compõe-se de dois minerais essenciais, quartzo e feldspato potássico e de minerais acessórios, sendo as micas brancas e pretas os mais frequentes.

Quartzito - Rocha metamórfica, compacta e dura. É constituída por mais de $80 \%$ de grãos de quartzo recristalizados.

\section{Aspectos a observar:}

- Contacto entre quartzitos e granitos;

- Diáclases;

- Arenização das rochas;

- Arenização das rochas.

Q5: Identifique as rochas que observa em afloramento:

Q6: Identifique e observe diáclases no afloramento. Porque se formam as diáclases?

Q7: $\overline{\text { Identifique o }}$ processo de alteração do granito:

Figura 3. Página 5 do guia de campo.

\section{Fase de síntese}

Após a aula de campo, procedeu-se à catalogação e identificação das amostras colhidas, recorrendo a uma análise macroscópica e comparando-as com amostras de mão existentes no laboratório. Posteriormente, foi efectuada uma análise final da actividade. Sem, Os discentes não identificaram qualquer constrangimento e foram unânimes em afirmar que foi muito positivo conhecer a 'sua' Serra noutra perspectiva. Sem excepção, esta foi a primeira aula de campo que estes alunos tiveram ao longo do seu percurso escolar, embora a maioria destes jovens habite nas imediações da Serra de Santa Helena e a visite com frequência, ainda não tinham tido a 
oportunidade de verificar "aquilo que aprendemos na sala de aula também se pode ver na nossa Serra".

\section{Avaliação}

Esta actividade foi avaliada na vertente das aprendizagens e do desenvolvimento de competências (conhecimentos, capacidades e atitudes), pelo guia de campo, e pela observação de aula, com o preenchimento, pela docente, de uma grelha construída para o efeito.

O guia de campo incluía um conjunto de catorze questões distribuídas pelos seis locais de observação. Na análise aos resultados, salienta-se que 15 alunos $(93,4 \%)$ responderam a todas as questões e 11 alunos $(68,8 \%)$ obtiveram como menção Satisfaz Bem na avaliação global do guia de campo (Tabela 1).

Tabela 1. Resultados da avaliação dos Guias de Campo.

\begin{tabular}{|c|c|c|c|c|c|}
\hline \multirow[t]{2}{*}{$\begin{array}{l}\text { Alunos } \\
\mathrm{N}^{\circ}\end{array}$} & $\begin{array}{c}\text { Resposta a } \\
\text { todas as } \\
\text { questões }\end{array}$ & $\begin{array}{c}\text { "Não Satisfaz" } \\
\geq 20 \% \text { e }< \\
50 \%\end{array}$ & $\begin{array}{c}\text { "Satisfaz" } \\
\geq 50 \% \text { e }< \\
70 \%\end{array}$ & $\begin{array}{c}\text { "Satisfaz } \\
\text { Bem" } \\
\geq 70 \% \text { e < } \\
90 \%\end{array}$ & \multirow{2}{*}{$\begin{array}{c}\text { "Excelente" } \\
\geq 90 \% \\
N^{\circ}(\%)\end{array}$} \\
\hline & $\mathrm{N}^{\circ}(\%)$ & $\mathrm{N}^{\circ}(\%)$ & $\mathrm{N}^{\circ}(\%)$ & $\mathrm{N}^{\circ}(\%)$ & \\
\hline 16 & $15(93,4)$ & $0(0,0)$ & $5(31,2)$ & $11(68,8)$ & $0(0,0)$ \\
\hline
\end{tabular}

Estes resultados podem considerar-se importantes, atendendo a que esta era uma turma com aproveitamento global mediano, tendo, na conclusão do ano lectivo, 4 alunos obtido, na avaliação final da disciplina de Ciências Naturais, o nível 2 (avaliação global anual de $\geq 20 \%$ e $<50 \%$ ) e apenas 4 o nível 4 (avaliação global anual de $\geq 70 \%$ e $<90 \%$ ).

Os parâmetros avaliados, com a grelha de observação da aula de campo (Tabela 2), registam uma classificação positiva. Salienta-se, nas atitudes, o "Interesse/atenção" e o "Respeito pelo meio envolvente" nas quais 11 alunos registam a menção Satisfaz Bem. Assinala-se ainda, a dificuldade revelada por 5 alunos na utilização de escala para incluir nas fotografias, em especial nas fotografias de pormenor, bem como em conseguir identificar correctamente in situ o local da paragem (4 alunos), situação que se pode dever a dificuldades em perceber a importância da escala e ler e interpretar mapas. 
Tabela 2. Resultados obtidos com a grelha de observação.

\begin{tabular}{cccccccc}
\hline \multirow{2}{*}{ Menção } & $\mathrm{A}$ & $\mathrm{B}$ & $\mathrm{C}$ & $\mathrm{D}$ & $\mathrm{E}$ & $\mathrm{F}$ & $\mathrm{G}$ \\
& $(\mathrm{N})$ & $(\mathrm{N})$ & $(\mathrm{N})$ & $(\mathrm{N})$ & $(\mathrm{N})$ & $(\mathrm{N})$ & $(\mathrm{N})$ \\
\hline Não Satisfaz & 0 & 4 & 5 & 0 & 3 & 0 & 0 \\
Satisfaz & 3 & 8 & 7 & 6 & 9 & 5 & 5 \\
Satisfaz Bem & 13 & 4 & 4 & 10 & 4 & 11 & 11 \\
\hline
\end{tabular}

A - Faz-se acompanhar do material necessário; B - Identifica o local de paragem; C - Usa escala para fotografar; D - Recolhe as amostras de mão adequadamente; $E$ - Mostra rigor na linguagem; F - Mostra Interesse/atenção; G - Respeita o meio envolvente; N - Número de alunos.

\section{Conclusão}

As vantagens das aulas de campo foram, mais uma vez, realçadas, embora esta aula tenha sido realizada no final do ano lectivo. As conclusões não devem ser generalizadas mas são importantes para o desenvolvimento de trabalhos futuros com objectivos semelhantes. Apesar de não serem ainda práticas muito comuns, as aulas de campo começam a ocupar um espaço nas estratégias dos docentes como actividades capazes de motivar os alunos para o interesse e estudo da Geologia.

A avaliação global mostra que esta actividade foi desenvolvida com sucesso e que o interesse e a disponibilidade manifestados foram bons indicadores da motivação dos alunos. Esta decorreu durante o período da aula de Ciências Naturais e sem o recurso a quaisquer encargos financeiros. Salientam-se estes factos, pois os maiores constrangimentos, associados à realização de aulas de campo, são os encargos financeiros e a dificuldade/impossibilidade em ocupar tempos lectivos de outras áreas curriculares. Neste contexto, realça-se: a importância em realizar aulas de campo numa área próxima da Escola, ultrapassando desta forma os encargos financeiros e o tempo ocupado; a importância e motivação que os discentes mostraram durante o estudo de exemplos da Geologia que lhes são próximos.

Realçam-se ainda as vantagens do recurso à planificação seguindo as orientações propostas por Orion, pois conhecer o roteiro e as paragens minimizou o impacto inicial do aluno ao contactar pela primeira vez com os locais a observar, numa perspectiva de aula de campo. $\mathrm{O}$ recurso a este modelo também proporcionou aos alunos um papel mais activo na 
aprendizagem, numa perspectiva construtivista, contribuindo para o desenvolvimento da sua autonomia.

Por fim, destaca-se a importância da observação in situ de exemplos da Geologia, porque podem ilustrar aqueles que foram estudados na sala de aula e facilitar a interpretação das grandezas físicas envolvidas nos processos geológicos.

Dedicatória: As autoras dedicam este estudo ao Professor Doutor Manuel Maria Godinho, associando-se à Homenagem ao Homem, ao Geólogo e ao Professor.

\section{Bibliografia}

Del Cármen, L., Pedrinaci, E. (1997) - El uso del entorno y el trabajo de campo. In Carmen L. (Coord.). La Enseñanza y el aprendizaje de las ciencias de la naturaleza en la educación secundária. Barcelona, I.C.E. Universitat Barcelona e Editorial Horsori, 133-154.

Dourado, L. (2001) - Trabalho Prático (TP), Trabalho Laboratorial (TL), Trabalho de Campo (TC) e Trabalho Experimental (TE) no Ensino das Ciências - contributo para a clarificação de termos. In Veríssimo, A.; Pedrosa, M.; Ribeiro, R.. Ensino Experimental das Ciências. (Re)pensar o Ensino das Ciências. Departamento do Ensino Secundário, Ministério da Educação. Lisboa, 13-18.

Google Earth, (2008) - http://earth.google.com (consultado em Maio/2010).

Hodson, D. (1988) - Experiments in science and science teaching. Educational philosophy and theory; $20(2), 53-66$.

Leite, E., Santos, M.R, (2004) - Nos Trilhos da Área-Projecto. Col. Desenvolvimento Curricular. Instituto de Inovação Curricular. IIE - Biblioteca Digital.

Marques, L., Praia, J. (2009) - Educação em Ciência: actividades exteriores à sala de aula. Terræ Didatica; 5 (1), 10-26 http://www.ige.unicamp.br/terraedidatica/ (acedido em Novembro de 2010).

Mason, J.L. (1980) - Annoted bibliography of field trip research. School, Science and Mathematics; $80(2), 155-166$.

Orion, N. (1989) - Development of a High-School Geology Course Based on Field Trips. Journal of Geological Education; 37. 13-17.

Orion, N. (1993) - A Model for the Development and Implementation of Field Trips as an Integral Part of the Science Curriculum. School Science and Mathematics; 93 (6), 325-331.

Orion, N. (2001) - Earth science education: from theory to practice - implementation of new teaching strategies in different learning environments. In Marques, L. \& Praia, J. (Coord.). Geociências nos Currículos dos Ensinos Básico e Secundário. Aveiro: Universidade de Aveiro; 261-282.

Orion, N., Hofstein, A. (1991) - The Measurement of Students' Attitudes Towards Scientific Field Trips. Science Education; 75 (5), 513-523.

Orion, N., Hofstein, A. (1994) - Factors that Influence Learning during a Scientific Field Trip in a Natural Environment. Journal of Research in Science Teaching; 31 (10), 1097-1119.

Orion, N., Hofstein, A., Mazor, E. (1986) - A field based high school geology course: Igneous and metamorphic terrains, an Israeli experience. Geology Teaching; 11, 16-20.

Ruivo, L., Guimarães, P., Patrão, I., Dantas, J., Dourado, L. (1995) - Trabalhos Práticos de Geologia bloco I. Edições ASA, Porto, 219-222. 
Silva, C.P., Amador, F., Baptista, J.F.P., Valente, R.A., Mendes, D., Rebelo, D., Pinheiro, E. (2001) Programa de Biologia e Geologia $10^{\circ}$ ano. Departamento do Ensino Secundário, Ministério da Educação. Lisboa; 97p.

Teixeira, C., Medeiros, A.C., Fernandes, A.P. (1969) - Carta Geológica de Portugal na escala 1/50 000, Notícia Explicativa Folha 14-A Lamego; Direcção-Geral de Minas e Serviços Geológicos de Portugal. 